\title{
Enhanced Optimal Feature Selection Techniques for Fetal Risk Prediction using Machine Learning Algorithms
}

\author{
J. Jayashree, Harsha T, Anil Kumar C, J. Vijayashree
}

\begin{abstract}
Cardiotocography (CTG) records fetal heart rate (FHR) and uterine contractions (UC) simultaneously. The CTG, which is one of the most common diagnostic techniques used during pregnancy and before delivery to evaluate maternal and fetal well-being. Doctors can understand the state of the fetus by observing the Cardiotocography trace patterns. There are several techniques for interpreting a typical cardiotocography data based on signal processing and computer programming. Only a few decades after cardiotocography has been implemented into clinical practice, the predictive potential of these approaches remains controversial and still unreliable This paper presents MRMR feature selection algorithms with four classification for Fetal risk prediction using python.
\end{abstract}

Keywords: Fetal heart rate, cardiotocography, uterine contractions, machine learning, MRMR, python.

\section{INTRODUCTION}

The innovative engineering methods have played an important role in the area of medicine, to help doctors achieve the desired outcomes effectively. The medical sector can't work efficiently, survive and improve its existence without engineering technology intervention, If traced back, that could be illustrated. Clinical studies are aiming to understand better the inner behavior of the human body over the decades. an area of medicine that needs immediate treatment from technical techniques is problems being faced by females during their pregnancy due to biological conditions deformity.

About 795 women dying from preventable sources of pregnancy and childbirth, of which $98 \%$ are in developing countries.

plummeted by $45 \%$ after 1990, the global maternal mortality ratio ( no of deaths per 100000 live birth) decreased by just 2.460\% per year between 1990 and 2015. According to some gynaecologists, every trimester is described as about 14 weeks, which adds to about 42 weeks of pregnancy. Around 20 million women worldwide suffer ill health every year as a result of pregnancy.

Revised Manuscript Received on February 05, 2020.

* Correspondence Author

J. Jayashree*, Assistant Professor Senior at VIT University, Vellore, Tamilnadu, India.

Harsha T, Assistant Professor Senior at VIT University, Vellore, Tamilnadu, India.

Anil Kumar, Department of Computer Science Engineering VIT Vellore

J.Vijayashree, Assistant Professor Senior at VIT University, Vellore, Tamilnadu, India.

(C) The Authors. Published by Blue Eyes Intelligence Engineering and Sciences Publication (BEIESP). This is an open access article under the CC BY-NC-ND license (http://creativecommons.org/licenses/by-nc-nd/4.0/)

In 1990, about 377,000 women died as a result of pregnancy complication, which dropped to 293,000 in 2013. Among those 288000 women have died during the delivery procedure andmost of the deaths where in low facilities settings and majority of them could have been saved. people who have suffered from problems while giving birth or after the procedure was performed. A professional practitioner's treatment before, during and after childbirth can save the live of pregnant women and newborn infants. Most maternal deaths are escapable, as the mechanisms for avoiding or treating complications.

\section{Fetal heart rate}

In the utero period, the general FHR fluctuates between 120-155 BPM. It is detectable sonographically from about 6 weeks and the range varies all through development, rising to about $170 \mathrm{bpm}$ at 70 days and then to about $130 \mathrm{bpm}$ at term. Although myocardium begins to contract rhythm 20 days after giving birth (from inspontaneity depolarizing myocardial pace maker cells in the embryonic heart), about 6 weeks of sonography gestation is first noticeable. Typically, the FHR then beats between 100 and 120 per minute (bpm).

FHR gradually fluctuates in the next 14-21days and becomes:

5-6 Weeks 110 bpm (mean)

$\sim 170$ bpm over 9-10 weeks

There after a drop in FHR becomes average:

$\sim 151$ bpm to 98 days

$\sim 142 \mathrm{bpm}$ to 140 dayss

131 bpm per term

Although the heartrate in the healthy fetus is normally normal, a beat-to-beat variation of about 5 to 14 beats per minute may be permitted.

\section{Fetal heart monitoring}

Fetal cardiac monitoring measures your baby's heart rate (fetus). This allows your health care provider to see how the child is healthy. Your health care provider will perform a fetal heart rate test in the later stages of pregnancy. In fetuses the normal heart rate varies from 110 to $160 \mathrm{bpm}$. It may range from 5-25 beats per minute. As your baby reacts to uterine conditions the fetal heart rate will change. An irregular fetal heart rate mean that baby isn't getting sufficient oxygen or other problem.

\section{A. External fetal heart monitoring}

We use a device to hear through patient belly (abdomen) and record your baby heartbeat. One type of display is an ultrasonic Doppler system. It's often used for monitoring the baby's heart pulse during prenatal visits. It also be used during labor to monitor fetal heart rate. 
The health care provider may also regularly monitor the baby's heart pulse during conception and childbirth.

To do this, your belly is fastened to the ultrasonic probe (transducer). It sends in a machine the sound of your baby's heart. The pattern and rate of heart rate for your baby is shown on a computer and written on paper.

Table1: Types of Fetal Monitoring Techniques.

\begin{tabular}{|c|c|c|}
\hline TYPES & DEFINATION & DIAGRAM \\
\hline $\begin{array}{l}\text { External } \\
\text { monitoring }\end{array}$ & $\begin{array}{l}\text { External } \\
\text { fetal heart } \\
\text { rate monitoring } \\
\text { uses a device to } \\
\text { detect or } \\
\text { record fetal } \\
\text { heart beat } \\
\text { through the } \\
\text { abdomen of the } \\
\text { mother. The } \\
\text { most specific } \\
\text { type of external } \\
\text { monitor is a } \\
\text { fetoscope (a } \\
\text { kind of } \\
\text { stethoscope). }\end{array}$ & External Fetal Monitor \\
\hline $\begin{array}{l}\text { Internal } \\
\text { monitoring }\end{array}$ & $\begin{array}{l}\text { An electrode is } \\
\text { placed along } \\
\text { the scalp of the } \\
\text { baby and it } \\
\text { passes through } \\
\text { the cervix from } \\
\text { the baby.the } \\
\text { heart rate and } \\
\text { the contractions } \\
\text { of the baby are } \\
\text { monitored } \\
\text { during labour } \\
\text { by the } \\
\text { healthcare } \\
\text { supplier. }\end{array}$ & 1 \\
\hline
\end{tabular}

\section{B. Internal fetal heart monitoring}

We insert a wire (electrode) that is placed on the scalp of the infant. The wire is going through your cervix from the infant. The monitor is linked. This method gives better readings, because it doesn't affect things like movement. But this can be achieved if the fluid-filled sac that protects baby during the pregnancy has separated and opened the cervix (amniotic sac).. If the external monitoring does not give a good reading, the provider may use internal monitoring. And your doctor may use this tool to take a closer look at your baby during labour.

The healthcare provider will monitor uterine contraction and heart rate of the baby during labour. Your provider should remember How often contractions do you experience \& how long each lasts. Because the heart rate and the contraction are fetal registered simultaneously, these findings can be interpreted and compared together.

Doctor can check pressure inside the uterus while doing internal fetal heart monitoring. To do so, doctor will put a tube (catheter) through the cervix and into uterus. The catheter shall forward uterine pressure reading to a monitor.

\section{Need of fetal heart monitoring}

Fetal heart rate monitoring is helpful if the patient have a high-risk pregnancy. If patient have diabetes or high bp, a high risk for the child. It is also high risk if the baby doesn't grow or develop as it should. Fetal heart rate monitoring can be used to check whether the child is affected by premature laboratory medicines. These are medications that help keep the work from getting started too early. Other research may also use fetal heart rate monitoring including:

A. Nonstress test : When the baby moves, this monitors the fetal heart rate.

B. Contraction stress test : It, along with uterine contractions, monitors fetal heart rate. Medicine or other approaches are used to initiate contractions.

C. A biophysical profile : This is combination of nonstress test with ultrasound.

\section{Risks of fetal monitoring}

For that study, radiation is not used. The transducer usually does not cause any pain.You can consider the elastic belts which slightly uncomfortable keep the transducers in place. These can be modified according to need.

During certain forms of fetal heart rate monitoring you have to lie still. At sleep, you may need to stay in bed. Patient may have some discomfort with internal testing when electrode is inserted into uterus. Internal monitoring risk include infection \& bruise of the scalp or other part of the baby's body.

Note: If you are HIV-positive you shouldn't have internal fetal heart rate monitoring. This is because you might pass the infection on to your kids.

Based on your particular health condition you may have other risks. Make sure to discuss any issues you may have with your provider prior to the instructions.

Certain things may or mayn't make the results of fetal heart rate monitoring less accurate. These include:

- Maternal obesity

- Baby position

- Too much fluid with amniotics (polyhydramnios)

Table2: Types of Fetal Diseases.

\begin{tabular}{|c|c|c|c|}
\hline & TYPE-1 & TYPE-2 & TYPE-3 \\
\hline NAME & Fetal Bradycardia & $\begin{array}{l}\text { Fetal } \\
\text { Tachycardia }\end{array}$ & $\begin{array}{l}\text { Fetal } \\
\text { Bradyarrhythm } \\
\text { ia(s) }\end{array}$ \\
\hline $\begin{array}{l}\text { DEFINITI } \\
\text { ON }\end{array}$ & 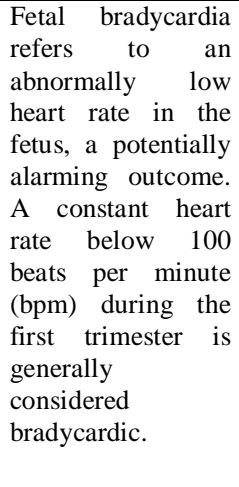 & $\begin{array}{l}\text { Fetal } \\
\text { tachycardia is } \\
\text { an anomalous } \\
\text { increase in } \\
\text { heart rate in } \\
\text { the fetal. If the } \\
\text { heart rate } \\
\text { above } 160-180 \\
\text { beats per } \\
\text { minute and } \\
\text { ranges from } \\
\text { 170-220 bpm } \\
\text { (high } \\
\text { tachyarrhythm } \\
\text { ias). }\end{array}$ & 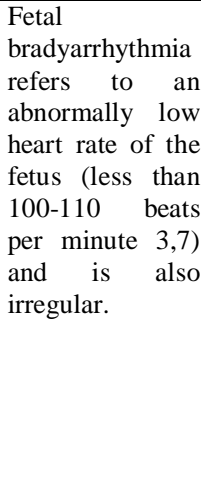 \\
\hline CAUSES & $\begin{array}{l}\square \text { poor } \\
\text { uterine perfusion }\end{array}$ & $\begin{array}{c}\square \\
\text { maternal fever }\end{array}$ & NILL \\
\hline
\end{tabular}




\begin{tabular}{|c|c|c|c|}
\hline & $\begin{array}{l}\square \\
\text { maternal hypotensi } \\
\text { on } \\
\square \\
\text { umbilical cord pro } \\
\text { lapse } \\
\square \\
\text { rapid fetal descent }\end{array}$ & $\begin{array}{l}\quad \square \\
\text { Dehydration } \\
\qquad \square \\
\text { maternal } \\
\text { ketosis } \\
\qquad \square \\
\text { preterm fetus } \\
\qquad \square \\
\text { maternal } \\
\text { thyrotoxicosis }\end{array}$ & \\
\hline $\begin{array}{l}\text { SYMPTO } \\
\text { MS }\end{array}$ & $\begin{array}{l}\quad \square \text { An } \\
\text { abnormally fast } \\
\text { heart rate. } \\
\quad \square \text { Abrupt } \\
\text { decreases in heart } \\
\text { rate. } \\
\qquad \quad \square \text { Late } \\
\text { returns to the } \\
\text { baseline heart rate } \\
\text { after a contraction. }\end{array}$ & $\begin{array}{c}\square \mathrm{An} \\
\text { abnormally } \\
\text { slow heart rate }\end{array}$ & NILL \\
\hline $\begin{array}{l}\text { HEART } \\
\text { RATE }\end{array}$ & $\begin{array}{l}\text { below } 100 \text { beats } \\
\text { per minute }(\mathrm{bpm})\end{array}$ & $\begin{array}{l}\text { above } 160-180 \\
\text { beats per } \\
\text { minute (bpm) }\end{array}$ & $\begin{array}{l}\text { less than } 100- \\
110 \text { beats per } \\
\text { minute. }\end{array}$ \\
\hline
\end{tabular}

\section{Cardiotocography Classification}

The National Institute of Child Health and Human Development is implementing CTG's framework for assessing FHR and uterine contraction trends. Listed below are only a few of the most important features for CTG data classification.

Baseline: The mean value of the Fetal Heart Rate data is defined as the baseline ranging from 100 to $160 \mathrm{bpm}$ for a 10 min period without acceleration or decelerations.

Variability: The variation spectrum in the FHR excluding the acceleration or deceleration is described as Variation. Depending on the time, this can be either short or long term. Accelerations and Decelerations: Acceleration is defined as an increase in FHR of more than $15 \mathrm{bpm}$ from baseline and lasting at least 15 seconds or higher. Acceleration is defined as a drop in FHR exceding 15 bpm from baseline and lasting at least 15 seconds or more. Drop in Fetal Heart Rate is characterized as early deceleration shortly after the onset of a Uterine contraction with peaks of deceleration and contraction facing one another. It is a clue to a healthy fetus. Category I FHR tracings provide baseline FHR with mild variation ranging from 110 to 160 . They lack variable and late decelerations, with early decelerations and accelerations possible.

Category II Tracings are those which can not be classified as either Category I or Category III. Such readings include: low or lack of variability, repeated decelerations, accelerations even after fetal activity, recurrent variable decelerations with no baseline variability.
Category III FHR levels are not common, and the risk of hypoxia and acidemia is higher. These either have repeated late decelerations or no variation in baseline, or sinusoidal pattern. Such readings are exceptional.

\section{Normal Fetal Heart Rate Chart By Week}

The fetal heart rate varies according to fetal gestational age. It begins at a slower rate may increases every day until around 12th week it stabilizes. The normal heart rate is between 120 and 160bpm around this gestation period. The chart below gives you an idea of how week by week the fetal heart rate varies.

Tables3: Fetal heart rate chart by week.

\begin{tabular}{|c|c|}
\hline $\begin{array}{c}\text { FETAL AGE } \\
\text { (by weeks) }\end{array}$ & $\begin{array}{c}\text { NORMAK FHR } \\
\text { (BPM) }\end{array}$ \\
\hline 5 & $80-103$ \\
\hline 6 & $103-126$ \\
\hline 7 & $126-149$ \\
\hline 8 & $149-172$ \\
\hline 9 & $120-180$ (avg 150) \\
\hline 12 & $120-160$ (avg 140) \\
\hline After 12 & \\
\hline
\end{tabular}

\section{LITERATURE REVIEW}

ANN approach for prediction of hypertension disease has been favoured in the studies. ANN's high cost of computation and long learning speeds enforce expanding the concept to deep learning network. Low computational costs and the classification of learning levels are therefore important for such problem. To enhance fetal risk prediction SVM hybrid response approaches were discussed with the other attribute reduction tool (Subha V et al. 2017).

This paper simultaneously studies the enhancement of Cardiotocogram data classification accuracy in the selection of features and classifiers based on ensemble learning. In the selection of features, two subset filtering techniques (Correlation-based Feature Selection; Consistency-based Filter) and two filter-based feature ranking techniques (Relief; Information Gain) are considered, while the Support Vector Machine classification technique is used in the classification (Silwattananusarn et al.2016).

Comparing the predictive accuracy of normal and pathological classifications (99.78 per cent), the findings performed much better than previous work[20 ] and were 99.2 per cent accurate when using Random Forests (Nagendra et al.2017).

Classification confusion matrix with minimum error of misclassification (0.184383) using pruned decision tree to analyze cardiotocogram data to determine fetal distress (Permanasari et al.2017).

CTG monitoring is useful for obstetricians in identifying fetal situations and in deciding on medical intervention during pregnancy and delivery before permanent baby damage (Zhang et al.2017). 
When validated, potential applications for this approach could include the use of lay doctors and nurses in remote critical care of pregnant women at high risk of severe perinatal outcome based on CTG tests, for clarity and further management.(Hoodbhoy et al.2019).

The study work analyzes the same data and found that ANN achieves overall accuracy as $92.42 \%$. The results from the CTG classification obtained in the paper suggest that the most accurate results are obtained from the decision treebased algorithm (J48) with 0.0408 as MAE, 0.8716 as kappa statistics and 94.33 per cent as accurate with the highest precision metric value. Classification of Random Forest and Regression was near J48 (Bhatnagar et al.2016).

Pre-processing of fetal heart monitoring data, sequential removal of fetal heart rate data for dataset removal with a high proportion of deletions, back to back missing values, linear interpolation, smooth denotation and then modification of the data structure to obtain three different data formats (Tang et al.2018).

Fetal distress assessed by discriminatory analysis, decision tree, and artificial neural network; results show that the accuracy of DT, ANN and DA is $86.36 \%, 97.78 \%$ and $82.1 \%$ respectively. The authors suggested using the classification techniques to fit into different attributes and apply feature techniques in the data processing preprocessing phase (Huang et al.2012).

The effect on classifiers of using AdaBoost ensemble is investigated for the perfect determination of the fetal distress from the results of CTG. The most prominent result is the AdaBoost decisionbased algorithm with 0.034 MAE, 0.861 kappa statistics and 95.01 percent accuracy, meaning 2126 samples will be perfectly predicted by 2020. These findings are a further improved next step, after the related literature studies (Karabulut et al.2014).

The application of the algorithm to the different stages of the pregnancy data provide an objective measure of the fetal health condition assessed in the author (Ersen et al.2013).

(Sundar C et al.2012) examined the output analysis of a CTG dataset based neural network classification model. The performance of the classification method, which was based on supervised machine learning, provided significant results. The classifier based on ANN was able to identify normal, suspicious and pathological conditions with very good accuracy from the nature of CTG data. ANN based classifier delivered excellent Rand Index, F-Score, Recall and Precision performance. It was able to identify with almost equal accuracy the normal and the pathological condition. Compared with other two classes, the performance in identifying the Suspicious CTG pattern was poor.

(Pooja Sharma et al.2012) A decisiontree algorithm and an existing C4.5 algorithm are proposed and implemented for the comparative study and performance analysis.

A Support Vector Machine algorithm was developed in com bination with empirical mode of decomposition to achieve $h$ igh compliance with Fetal Heart Rate data prediction with e xpert clinical interpretation(krupa et al.2011).

(Kalpesh et al.2013) developed a system that uses data mining concepts to predict students performance from their previous performances. We have applied classification algorithms ID 3 and C4.5 to student data and estimated the overall and individual performances of newly admitted students in future exams.

(Yugal et al.2012) focus on basic data mining classification techniques such as the BayesNet, NavieBayes, NavieBayes Uptable, Multilayer Perceptron, Voted Perceptron and J48 (C4.5) classifiers. These algorithms are used to classify the dataset, and their performance is analyzed by means of absolute error, root mean square error and the time taken to construct the model. The decision tree C4.5 algorithm used by (Hamidah et al.2010) to create the rules for classifying human talent data. The rules produced are evaluated using the unidentified data to approximate the precision of the prediction results.

Other author, however, argued the importance of hybrid data mining algorithms to a pregnant women's build model, prevention of health risks caused by inconsistencies in parameters during pregnancy. The C4.5 algorithm delivered exact performance of 98 per cent (Lakshmi et al . 2016).

My aid in better predicting fetal growth during pregnancy is the proper dataset consisting of the correct number of parameters and applying the hybrid approaches. Similarly, eight machine learning algorithms have been documented using weka tools over the CTG dataset in other studies. The exact prediction response of all algorithms was analyzed for validation by partitioning the dataset into ten equal size. The performance of the classifier model, the highest precise classification was scored 99.2 percent. Feedforward NN solved ANN drawbacks with non-linear functions which composed a number of weighing inputs, hidden layers followed by initiation function, a bias that provides output for the next layers (Kalyani et al.2018).

Table4: Related data

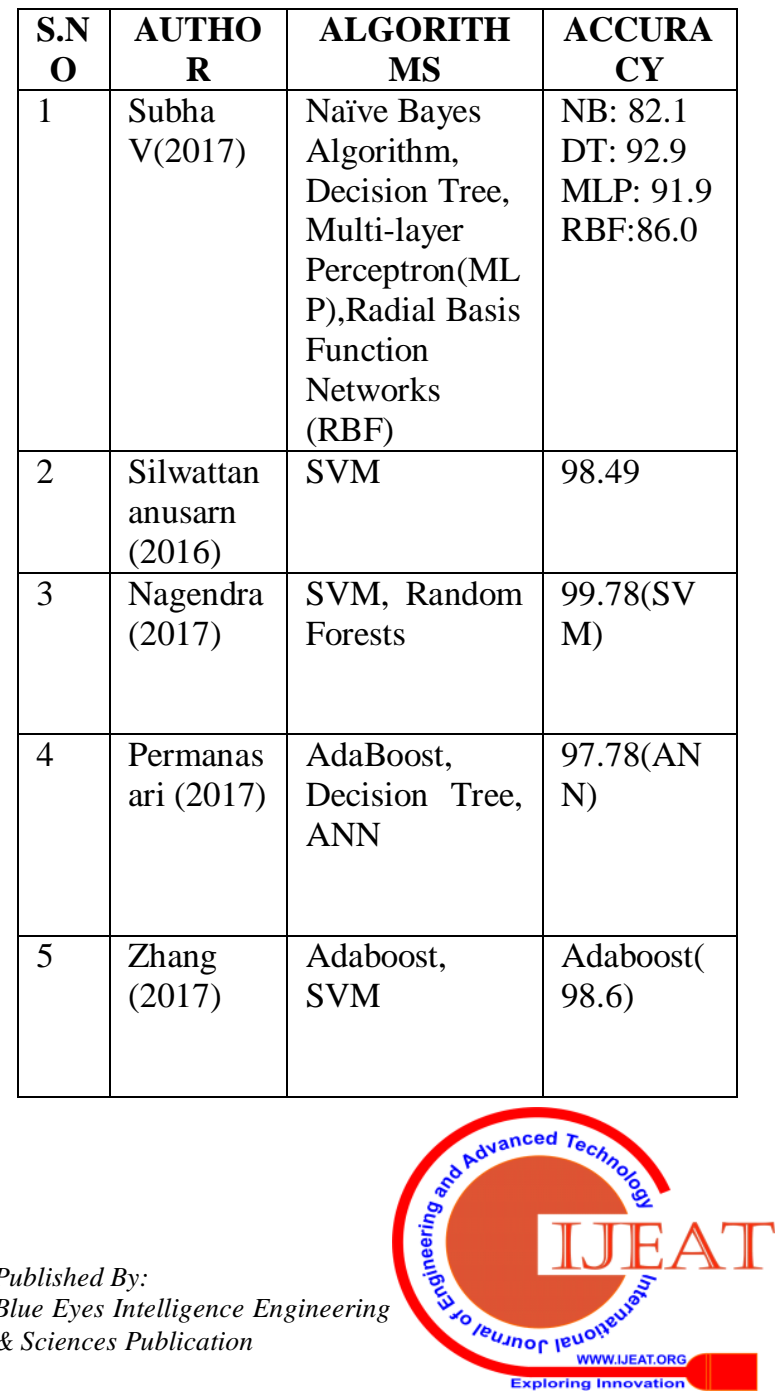




\begin{tabular}{|c|c|c|c|}
\hline 6 & $\begin{array}{l}\text { Hoodbho } \\
\text { y (2019) }\end{array}$ & $\begin{array}{l}\text { MLP, Decision } \\
\text { Tree, Random } \\
\text { Forest, } \\
\text { Logistic } \\
\text { Regression, } \\
\text { SVM, KNN }\end{array}$ & 97(SVM) \\
\hline 7 & $\begin{array}{l}\text { Bhatnaga } \\
\text { r (2016) }\end{array}$ & $\begin{array}{l}\text { Naïve } \\
\text { Bayesian } \\
\text { Classifier, } \\
\text { Decision Tree, } \\
\text { Random } \\
\text { Forest, } \\
\text { JRIP,,MultiLay } \\
\text { er Perceptron, } \\
\text { ANN }\end{array}$ & $\begin{array}{l}\text { 92.42(AN } \\
\mathrm{N})\end{array}$ \\
\hline 8 & $\begin{array}{l}\text { Tang } \\
\text { (2018) }\end{array}$ & $\begin{array}{l}\text { SVM, Random } \\
\text { Forest, } \\
\text { MKNet, } \\
\text { MKRNN }\end{array}$ & $\begin{array}{l}94.7(\mathrm{SVM} \\
)\end{array}$ \\
\hline 9 & $\begin{array}{l}\text { Huang } \\
\text { (2012) }\end{array}$ & DA, DT, ANN & $\begin{array}{l}97.78(\mathrm{AN} \\
\mathrm{N})\end{array}$ \\
\hline 10 & $\begin{array}{l}\text { Karabulut } \\
\text { (2014) }\end{array}$ & $\begin{array}{l}\text { Naïve Bayes, } \\
\text { Radical Basis } \\
\text { Function, } \\
\text { SVM, Neural } \\
\text { Network, DT }\end{array}$ & $\begin{array}{l}\text { DT with } \\
\text { AdaBoost( } \\
95.014) \\
\text { DT } \\
\text { without } \\
\text { AdaBoost( } \\
92.427)\end{array}$ \\
\hline 11 & $\begin{array}{l}\text { Ersen } \\
\text { YJlmaz } \\
(2013)\end{array}$ & LS-SVM & 91.62. \\
\hline 12 & $\begin{array}{l}\text { Sundar C } \\
\text { (2012) }\end{array}$ & ANN & 97.24. \\
\hline 13 & $\begin{array}{l}\text { Pooja } \\
\text { Sharma } \\
(2012)\end{array}$ & Decision Tree & 77.23 \\
\hline 14 & $\begin{array}{l}\text { Niranjana } \\
\text { Krupa } \\
(2011)\end{array}$ & ANN,SVM & 86 \\
\hline 15 & $\begin{array}{l}\text { Kalpesh } \\
\text { Adhatrao } \\
(2013)\end{array}$ & ID3,C4.5 & 75.14 \\
\hline 16 & $\begin{array}{l}\text { Yugal } \\
\text { Kumar } \\
(2012)\end{array}$ & Naïve Bayes & 97.28 \\
\hline 17 & $\begin{array}{l}\text { Lakshmi } \\
\text { B.N } \\
(2015)\end{array}$ & Decision tree & 98 \\
\hline 18 & $\begin{array}{l}\text { Hamidah } \\
\text { Jantan } \\
(2010)\end{array}$ & SVM,AIS,C4.5 & 77 \\
\hline 19 & $\begin{array}{l}\text { Kalyani } \\
\text { (2015) }\end{array}$ & $\begin{array}{l}\text { RF,C4.5,SVM, } \\
\text { CART,ANN, } \\
\text { K-NN }\end{array}$ & 98.67 \\
\hline 20 & $\begin{array}{l}\text { Daniel } \\
\text { LaFrenier } \\
\text { e (2016) }\end{array}$ & ANN & 82 \\
\hline
\end{tabular}

Retrieval Number: C6502029320 /2020@BEIESP DOI: 10.35940/ijeat.C6502.029320

Journal Website: www.ijeat.org

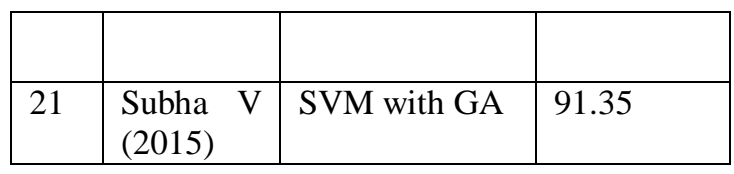

\section{Methodology:}

Minimum Redundancy Maximum Relevance technique is used for selecting the features which has high correlation with the class and low correlation with other features in the dataset. The selected features are then classified using the following algorithms: Navies Bayes, Decision Tree, Random Forest, Support Vector Machine.

Figure 1 depicts the System Architecture Diagram

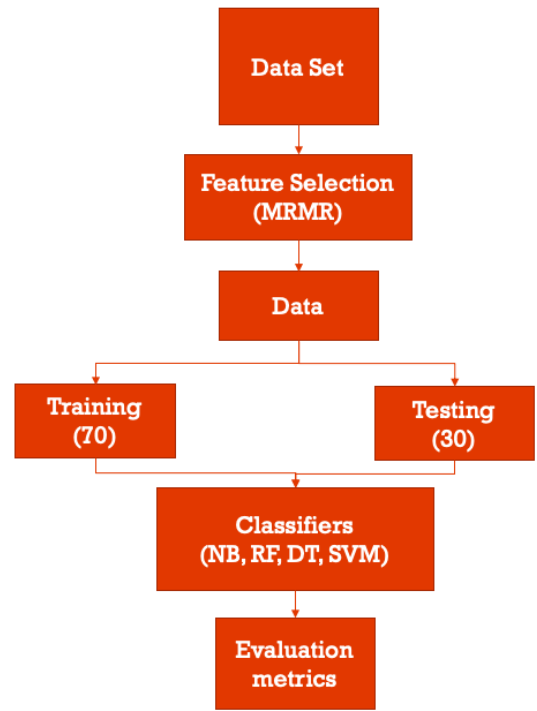

Fig. 1 System Architecture

\section{Result analysis}

The performance of the proposed work is analyzed using the following metrics: accuracy, precision, recall and F-score. Table 5 representsthe comprasion between the classifiers terms of accuracy which is figured in fig. 2

Table5: Comparison results of classifiers with regard to Accuracy

\begin{tabular}{|c|c|c|c|}
\hline \multicolumn{4}{|c|}{ Accuracy in \% } \\
\hline $\begin{array}{c}\text { Classifiier } \\
\text { s }\end{array}$ & $\begin{array}{c}\text { No . of } \\
\text { f } \\
\text { feature } \\
\text { s-20 }\end{array}$ & $\begin{array}{c}\text { No .of . } \\
\text { features- } \\
25\end{array}$ & $\begin{array}{c}\text { No .of . } \\
\text { features- } \\
30\end{array}$ \\
\hline $\begin{array}{c}\text { Naives } \\
\text { Bayes }\end{array}$ & 88 & 90 & 98 \\
\hline $\begin{array}{c}\text { Random } \\
\text { Forest }\end{array}$ & 96 & 97 & 98 \\
\hline $\begin{array}{c}\text { Decision } \\
\text { Tree }\end{array}$ & 95 & 97 & 98 \\
\hline SVM & 95 & 94 & 98 \\
\hline
\end{tabular}


Enhanced Optimal Feature Selection Techniques for Fetal Risk Prediction using Machine Learning Algorithms

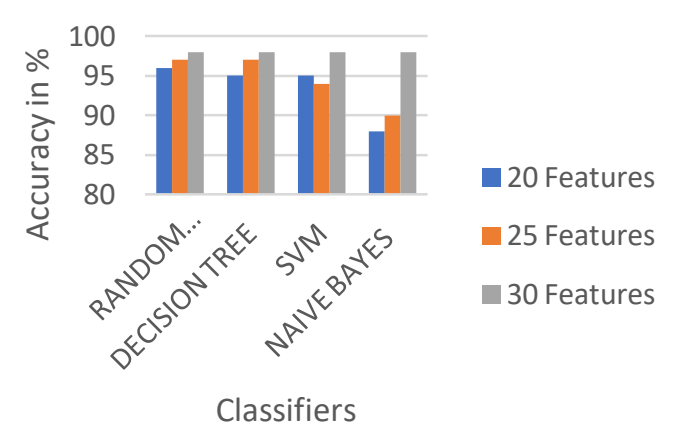

Fig. 2 Comparison results of classifiers with regard to Accuracy

Table 6 representsthe comprasion between the classifiers terms of accuracy which is figured in fig. 3

Table6: Comparison results of classifiers with regard to Precision

\begin{tabular}{|c|c|c|c|}
\hline \multicolumn{4}{|c|}{ Precision in \% } \\
\hline $\begin{array}{c}\text { Classifiier } \\
\text { s }\end{array}$ & $\begin{array}{c}\text { No . of } \\
\text { features } \\
-20\end{array}$ & $\begin{array}{c}\text { No .of . } \\
\text { features- } \\
25\end{array}$ & $\begin{array}{c}\text { No .of . } \\
\text { features- } \\
30\end{array}$ \\
\hline $\begin{array}{c}\text { Naives } \\
\text { Bayes }\end{array}$ & 73.6 & 76.6 & 97 \\
\hline $\begin{array}{c}\text { Random } \\
\text { Forest }\end{array}$ & 88.3 & 94 & 95 \\
\hline $\begin{array}{c}\text { Decision } \\
\text { Tree }\end{array}$ & 86 & 93.6 & 94.6 \\
\hline SVM & 83.6 & 83.6 & 97.3 \\
\hline
\end{tabular}

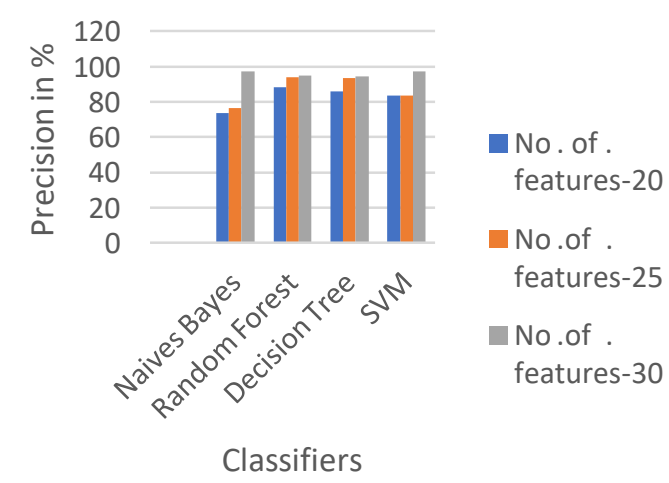

Fig. 3 Comparison results of classifiers with regard to Precision

Table 7 representsthe comprasion between the classifiers terms of accuracy which is figured in fig. 4

Table7: Comparison results of classifiers with regard to Sensitivity

Sensitivity in \%

\begin{tabular}{|c|c|c|c|}
\hline Classifiiers & $\begin{array}{c}\text { No . of . } \\
\text { features } \\
-20\end{array}$ & $\begin{array}{c}\text { No .of . } \\
\text { features-25 }\end{array}$ & $\begin{array}{c}\text { No .of . } \\
\text { features-30 }\end{array}$ \\
\hline $\begin{array}{c}\text { Naives } \\
\text { Bayes }\end{array}$ & 83.3 & 85.6 & 94 \\
\hline $\begin{array}{c}\text { Random } \\
\text { Forest }\end{array}$ & 91 & 95.3 & 95 \\
\hline $\begin{array}{c}\text { Decision } \\
\text { Tree }\end{array}$ & 90.6 & 95 & 96.6 \\
\hline SVM & 85.6 & 88 & 97.6 \\
\hline
\end{tabular}

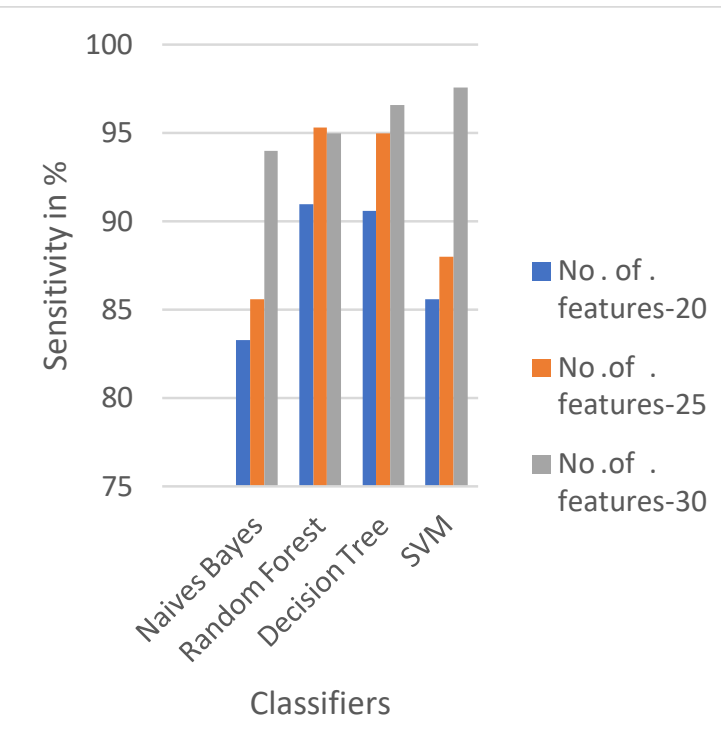

Fig. 4 Comparison results of classifiers with regard to Sensitivity

Table 8 representsthe comprasion between the classifiers terms of accuracy which is figured in fig. 5

Table8: Comparison results of classifiers with regard to F-score

\begin{tabular}{|c|c|c|c|}
\hline \multicolumn{4}{|c|}{ F-score in \% } \\
\hline Classifiiers & $\begin{array}{c}\text { No . of . } \\
\text { features- } \\
20\end{array}$ & $\begin{array}{c}\text { No .of . } \\
\text { features-25 }\end{array}$ & $\begin{array}{c}\text { No .of . } \\
\text { features-30 }\end{array}$ \\
\hline $\begin{array}{c}\text { Naives } \\
\text { Bayes }\end{array}$ & 75.3 & 79.3 & 95.66 \\
\hline $\begin{array}{c}\text { Random } \\
\text { Forest }\end{array}$ & 89.3 & 94.3 & 95.3 \\
\hline $\begin{array}{c}\text { Decision } \\
\text { Tree }\end{array}$ & 88 & 94.3 & 96 \\
\hline SVM & 84.3 & 84.6 & 97.6 \\
\hline
\end{tabular}




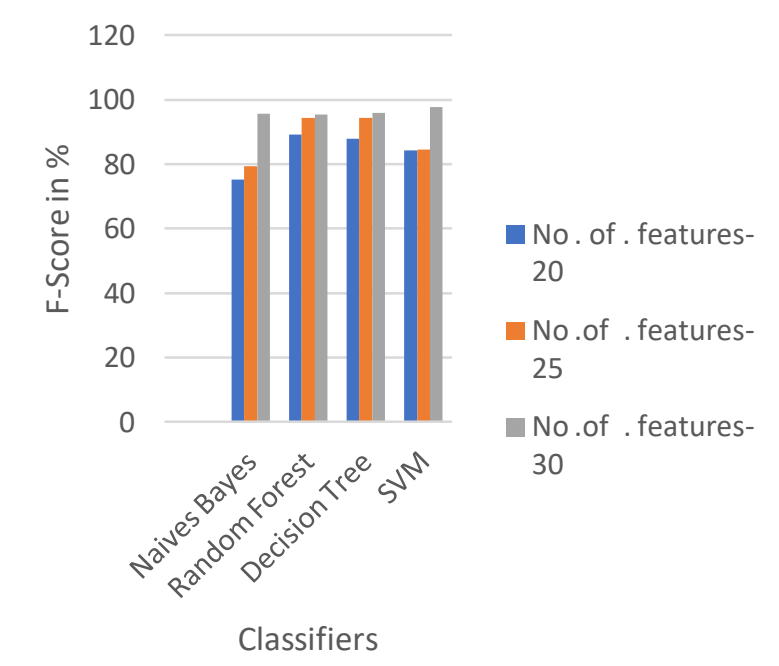

Fig. 5 Comparison results of classifiers with regard to Fscore

\section{CONCLUSIONS}

Thus the paper examines the Fetal Risk Prediction using MRMR Feature Selection algorithm on four different Classifiers SVM Classifier with high F-score(97.6), sensitivity(97.6) , Precision(97.3).SVM Classifier have got the maximum metrics percentage for MRMR Feature selection algorithm.

\section{REFERENCES}

1. 1.Subha, V., D. Murugan, and A. Manivanna Boopathi. "A hybrid filter-wrapper attribute reduction approach for fetal risk anticipation." Asian Journal of Research in Social Sciences and Humanities 7.2 (2017): 1094-1106.

2. Silwattananusarn, Tipawan, Wanida Kanarkard, and Kulthida Tuamsuk. "Enhanced classification accuracy for cardiotocogram data with ensemble feature selection and classifier ensemble." Journal of Computer and Communications 4.4 (2016): 20-35.

3. Nagendra, Vinayaka, et al. "Evaluation of support vector machines and random forest classifiers in a real-time fetal monitoring system based on cardiotocography data." 2017 IEEE Conference on Computational Intelligence in Bioinformatics and Computational Biology (CIBCB). IEEE, 2017.

4. Permanasari, Adhistya Erna, and Akhsin Nurlayli. "Decision tree to analyze the cardiotocogram data for fetal distress determination." 2017 International Conference on Sustainable Information Engineering and Technology (SIET). IEEE, 2017.

5. Zhang, Yang, and Zhidong Zhao. "Fetal state assessment based on cardiotocography parameters using PCA and AdaBoost." 2017 10th International Congress on Image and Signal Processing, BioMedical Engineering and Informatics (CISP-BMEI). IEEE, 2017.

6. Hoodbhoy, Zahra, et al. "Use of machine learning algorithms for prediction of fetal risk using cardiotocographic data." International Journal of Applied and Basic Medical Research 9.4 (2019): 226.

7. Bhatnagar, Divya, and Piyush Maheshwari. "Classification of cardiotocography data with WEKA." International Journal of Computer Science and Network-IJCSN 5.2 (2016).

8. Tang, Haijing, et al. "The Design and Implementation of Cardiotocography Signals Classification Algorithm Based on Neural Network." Computational and mathematical methods in medicine 2018 (2018).

9. Huang, Mei-Ling, and Yung-Yan Hsu. "Fetal distress prediction using discriminant analysis, decision tree, and artificial neural network." (2012).

10. Karabulut, Esra Mahsereci, and Turgay Ibrikci. "Analysis of cardiotocogram data for fetal distress determination by decision tree based adaptive boosting approach." Journal of Computer and Communications 2.9 (2014): 32-37.

11. Yılmaz, Ersen, and Çağlar Kılıkçıer. "Determination of fetal state from cardiotocogram using LS-SVM with particle swarm optimization and binary decision tree." Computational and mathematical methods in medicine 2013 (2013)

J.Vijayashree received PG degree and PhD from VIT University,Tamilnadu. She is working as Assistant Professor Senior at VIT University, Vellore, Tamilnadu, India. Her research interests include Data Mining, Machine Learning. She had published a good number of papers in reputed Scopus Indexed Journals. 